\title{
PESQUISAS EM ANIMAIS: UMA REFLEXÃO BIOÉTICA
}

Ana Lúcia Franco ${ }^{1}$, Marianne Nicole M. Nogueira ${ }^{2}$, Natália Guimarães Kalatzis Sousa ${ }^{3}$, Matheus Franco da Frota ${ }^{3}$, Clemente Maia S. Fernandes ${ }^{4}$, Mônica da Costa Serra ${ }^{5}$

Resumo: Os modelos de experimentação animal constituem uma importante ferramenta na pesquisa científica. Sabe-se que essa prática deve estar baseada em princípios bioéticos, seja para impor limites de dor e sofrimento, como para fiscalizar instalações e procedimentos. Assim, o presente estudo teve por objetivo levantar e apresentar as normas atuais que regulamentam as pesquisas em animais no Brasil comprando-as a outros países, bem como fomentar reflexôes bioéticas sobre esse mote. Para isso, apresentamos a legislação brasileira vigente e conduzimos uma revisão e discussão da literatura internacional. A busca de artigos foi realizada na base de dados PubMed, utilizando como palavra-chave os termos "bioética" e "bem-estar do animal". Foram incluídos dezenove artigos, publicados entre os anos de 1997 a 2013. Concluiu-se que é evidente a contribuição dos animais para pesquisas científicas de diversas áreas. Cabe moralmente ao Homem, como ser racional, garantir um tratamento digno aos animais que contribuem para a pesquisa. A forma mais segura de seguir este caminho é estabelecendo leis claras e pesquisas bem delineadas, que envolvam a sociedade para designar normas éticas. Dessa forma, o bem-estar animal estaria garantido.

Palavras-chave: bioética, ética em pesquisa, experimentação animal, bem-estar do animal

\section{Investigación con animales: una reflexión bioética}

Resumen: Los modelos animales son una herramienta importante en la investigación científica. Se sabe que esta práctica debe basarse en principios bioéticos, sea para imponer límites sobre el dolor y el sufrimiento, o para inspeccionar las instalaciones y procedimientos. Este estudio tuvo el objetivo de evaluar y presentar las normas vigentes que rigen la investigación con animales en Brasil, comparándolas con otros países, así como fomentar la reflexión bioética sobre este tema. Para eso, presentamos la legislación brasileña vigente y realizamos una revisión y discusión de la literatura internacional. La búsqueda de artículos fue realizada en la base de datos PubMed, usando las palabras-clave "bioética" y "bienestar del animal". Se incluyeron diecinueve artículos publicados entre 1997 e 2013. Se concluyó que es evidente la contribución de los animales para la investigación científica de varias áreas. Cabe moralmente al ser humano, como ser racional, asegurar un tratamiento humanitario de los animales que contribuyen con la investigación. La forma más segura de seguir este camino es estableciendo leyes claras e investigaciones bien delineadas, que involucren la sociedad para designar normas éticas. Así, el bienestar de los animales estaría garantizado.

Palabras clave: bioética, ética en investigación, experimentación animal, bienestar del animal

\section{Animal research. A bioethical reflection}

\begin{abstract}
Animal models are an important tool in scientific research. It is known that this practice must be based on bioethical principles in order to impose limits about pain and suffering, or for inspecting proceedings and research site. This study has as aim to evaluate and present current legislation ruling animal research in Brazil, comparing it with other countries, as well as fostering bioethical reflection about this issue. For this, we present current Brazilian legislation and we have carried out international literature review and discussion. The articles were searched in PubMed data base, using the key words "bioethics" and "animal welfare". Nineteen articles from 1997 to 2013 were included. It was concluded the evident contribution of animal research for scientific research in several fields. It is morally relevant for humans, as rational beings, to secure humane treatment to animals contributing to research. The safest way to follow this path is establishing clear norms and studies well designed, involving society for assigning ethical norms. Thus, animal welfare would be guarantee.
\end{abstract}

Key words: bioethics, research ethics, experimentation with animals, animal welfare

\footnotetext{
${ }^{1}$ Departamento de Materiais Odontológicos e Prótese, Faculdade de Odontologia de Araraquara - Univ. Estadual Paulista, Brasil Correspondência: analu.franco@hotmail.com

${ }^{2}$ Departamento de Periodontia, Faculdade de Odontologia de Araraquara - Univ. Estadual Paulista, Brasil

${ }^{3}$ Departamento de Endodontia, Faculdade de Odontologia de Araraquara - Univ. Estadual Paulista, Brasil

${ }^{4}$ Universidade de São Paulo, Brasil

${ }^{5}$ Departamento de Odontologia Social, Disciplina de Ética e Bioética, Faculdade de Odontologia de Araraquara - Univ. Estadual Paulista, Brasil
} 


\section{Introdução}

Ao se buscar evidências sobre o uso de animais pelo Homem, percebe-se uma relação antiga. Os animais têm sido usados como fonte de alimentos, de esporte, de lazer, na religião e no transporte, visando ao conforto humano. Entretanto, as preocupaçóes com o bem-estar animal foram negligenciadas por muitos anos. No século XIII, por exemplo, São Tomás de Aquino afirmava que os animais não possuíam alma e, portanto, deveriam receber o mesmo tratamento que objetos inanimados $(1,2)$.

Em 1876, o "Cruelty to Animals Act" buscou doutrinar a pesquisa em animais. Apesar do esforço, essa proposta não foi bem recebida pela comunidade científica da época. Em 1927 surgiu o primeiro documento sobre bioética, no qual o Dr. Fritz Jarh idealizou que "todos os seres vivos teriam direito ao respeito"(3). Em 1949, o Código de Nuremberg, primeiro documento internacional sobre ética em pesquisa envolvendo seres humanos, ressaltou que os experimentos em humanos deveriam ser baseados nos resultados de estudos prévios em animais. Assim, embora o uso de animais em pesquisas estivesse justificado, não havia nenhuma norma ou diretriz legal que o regulamentasse. Para esse fim, Russel e Burch ${ }^{4}$, em 1959, propuseram uma filosofia denominada "Princípio dos três R: replacement, reduction e refinement". Segundo a mesma, replacement significa trocar animais de desenvolvimento superior por formas de vida mais primitivas; reduction sugere a maior redução possível do número de animais a serem utilizados em um experimento e refinement indica a reduçáo do sofrimento dos animais, visando ao maior conforto dos mesmos durante a execuçáo do experimento $(1,4)$.

Durante muito tempo, o bem-estar animal se restringiu somente à redução do estresse, enquanto o sofrimento era negligenciado. $\mathrm{Na}$ década de 90 , a comunidade científica iniciou uma abordagem diferente sobre as pesquisas em animais. Com isso, os sentimentos dos mesmos foram considerados e as emoçóes positivas (prazer, conforto, contentamento, curiosidade e ludicidade) passaram a ter um papel importante no conceito de bem-estar animal. No século XXI surgiram novas divergências sobre o assunto, dando vazão a cres- centes discussões éticas $(2,5)$.

Atualmente, os modelos de experimentação animal constituem uma forte ferramenta na pesquisa científica. Assim, é imprescindível que os pesquisadores conheçam e entendam a legislação que regulamenta essa prática, para que possam conciliar os conceitos de bioética e garantir boa credibilidade dos resultados(6). Em vista disso, o presente estudo tem por objetivo levantar e apresentar as normas atuais que regulamentam as pesquisas em animais no Brasil e em outros países, bem como fomentar reflexóes bioéticas sobre esse mote.

\section{Material e método}

Para o desenvolvimento do presente estudo, foram levantadas e apresentadas as normas atuais que regulamentam as pesquisas em animais no Brasil comparando-as àquelas existentes em países da Europa e África. Além disso, propusemos uma atualização da literatura internacional sobre o assunto. A busca de artigos científicos foi realizada na base de dados PubMed, utilizando como palavra-chave os termos "bioética" e "bem-estar do animal". Foram incluídos dezenove artigos, publicados entre os anos de 1997 a 2013.

\section{Revisáo da literatura e discussáo}

\section{Leis que regulamentam a pesquisa em animais}

Uma linha muito tênue separa atitudes éticas de procedimentos repreensíveis. Por isso, a prática da pesquisa animal deve estar baseada em princípios bioéticos, seja para impor limites de dor e sofrimento, como para fiscalizar instalações e procedimentos. ${ }^{1}$ Cada país apresenta uma legislação específica para pesquisas em animais e, quanto mais desenvolvida a nação, mais regras são impostas. Muitos centros de pesquisa, diante das rígidas imposiçóes de seus comitês de ética, têm buscado parcerias com regióes menos desenvolvidas - isto é, com legislação menos severa - para a prática de seus experimentos (2,7-9).

No Brasil, a lei $6.638 / 79$ foi a primeira a estabelecer normas para a prática didático-científica em animais; entretanto, a mesma ainda não abordava o princípio dos " $3 \mathrm{R}$ ". O projeto de lei 3964/97, além de adotar o princípio, estabeleceu 
a criação da Comissão de Ética para o Uso de Animais (CEUA) e propôs a criação do Conselho Nacional de Controle de Experimentação Animal (CONCEA), órgão normativo, credenciador, supervisor e controlador das atividades de pesquisa em animais. Dez anos depois, em 2008, a lei federal $n^{\circ} 11.994$, conhecida como lei Arouca, regulamentou os CEUAs e criou o CONCEA. O decreto $n^{\circ}$ 6.899/2009 regulamentou a lei Arouca e criou o Cadastro das Instituiçôes de Uso Científico de Animais (CIUCA). O CEUA é indispensável para o cadastramento das instituiçóes, sendo composto por cidadáos de notório saber que examinam os protocolos e buscam compatibilidade com a legislação. O CONCEA determina as normas para o cuidado, as instalaçóes dos centros de criação, o uso humanitário, além da busca de técnicas alternativas para a substituição do uso de animais. $\mathrm{O}$ não cumprimento dessas normas implica em penalidades, que variam entre advertências, multas e interdiçôes $(6,10,11)$.

$\mathrm{Na}$ Europa, avanços no que diz respeito ao bem estar animal já foram atingidos. Em 2010 houve uma revisão das diretrizes que regulamentam as pesquisas em animais (2010/63-EU), apesar de certas questóes importantes ainda não haverem sido abordadas. A proposição dessas diretrizes inclui o uso do Princípio dos três " $R$ ", a preocupação com o bem-estar animal e a consequente eliminação da dor, sofrimento e angústia. Para tanto, propóe-se o uso eficaz de anestésicos e analgésicos, além de cuidados na criação, alojamento, e um médico veterinário responsável pela condução do experimento. Além disso, os dados dos estudos deveriam ser compartilhados para evitar a duplicação desnecessária de experimentos. Como consequência, nos países que fazem parte da Uniẫo Europeia, o trabalho é dificultado pelo custo elevado e pelas diversas restriçóes estabelecidas. Motivados pelo impulso econômico, esses experimentos têm sido empurrados para fora dos países desenvolvidos, onde encontram maiores facilidades de execução(9).

Uma das diferenças encontradas entre as diretrizes europeias e a legislação brasileira diz respeito à equipe responsável pela supervisão do cuidado animal. Na Europa, fica claro que deve haver um profissional competente responsável (médicos veterinários e/ou zootecnistas), enquanto no
Brasil apenas há menção de que o profissional seja graduado ou pós-graduado na área biomédi$\mathrm{ca}(6,8-11)$.

No continente africano, alguns países como o Quênia desenvolvem pesquisas em primatas não humanos e em camundongos; um dos exemplos de estudos desenvolvidos é o efeito imunológico da co-infecção da esquistossomose e malária, doença comum naquele país. Nesses centros, os departamentos são bem equipados com modernas instalaçóes e existe a atenção ao cuidado com o animal. Na Etiópia, macacos são usados como modelos de estudo da leishmaniose, no Zimbábue vacinas são testadas em ratos e na África do Sul coelhos são usados para testar terapêuticas contra o vírus do papiloma humano. Pode-se observar que diversos centros universitários desenvolvem pesquisas em animais de importância e relevância para a comunidade africana, e a preocupação com o animal não é negligenciada, uma vez que existe um esforço da comunidade científica em manter instalaçôes bem cuidadas e equipadas. No entanto, a maioria dos países africanos esbarra na dificuldade de acesso a informaçóes de domínio público, referentes aos protocolos e cuidados com pesquisas em animais, abrindo precedentes para o descaso. Como não há acesso às leis, cada centro de pesquisa pode estabelecer as suas normas, sem o cuidado com a prestaçáo de contas com a comunidade, o que pode dar vazão à instalação de abusos contra os animais(8).

\section{Reflexóes bioéticas}

A bioética é um termo que rege as diferentes tentativas de se humanizar a abordagem científica, a prática dos profissionais de saúde e o respeito aos direitos humanos na economia, na política e na pesquisa social(1). Assim, as questóes acerca de como os animais devem ser usados e tratados saem do contexto exclusivo da ciência, requerendo reflexóes em valores sociais e conceitos de ética aplicada. Isso porque as consideraçóes éticas são emocionais, enquanto a ciência é racional, objetiva e livre de valores. Deve-se, portanto, buscar soluçôes eticamente responsáveis e viáveis, que beneficiem tanto os animais em si, como os homens e o meio ambiente(7). 
Normalmente, os conflitos éticos giram em torno dos três princípios-base propostos pela Matriz Ética(12), que consistem em: 1. respeito aos seres humanos, 2. respeito à autonomia e 3. respeito à justiça. No meio acadêmico e científico, além destes princípios, deve-se levar em consideração aspectos como a deliberação consciente - atenta às preocupaçóes enfrentadas pelas partes interessadas - e a necessidade de uma abordagem pluralista - confrontando ideais das diversas partes, baseando-se em princípios relevantes, que reflitam como cada parte será afetada por um curso particular de ação $(7,12)$.

O chamado "Processo de Avaliação Ética de Campbell" (13) consiste em uma ferramenta mais completa para a resolução dos conflitos éticos. Basicamente, a avaliação gira em torno de seis princípios-base, que incluem: 1 . identificação do problema e das partes interessadas, 2 . busca de fatos que justifiquem a tomada de decisão (evidence-based science), 3. reflexão moral sobre os objetivos e os meios de atingi-los, 4. determinação de valores com importância moral, 5. determinação de uma justificativa moral eticamente aceita e 6 . testes de opiniáo sobre danos, viabilidade, publicidade, colegialidade, reversibilidade e apoio ético $(7,13)$.

Mais recentemente, tem sido discutido o conceito de vulnerabilidade dos animais em experimentação, conceito que pode favorecer a abordagem em ética animal. Esse conceito permite a identificação de deficiências no tratamento animal, formando uma base para articular as obrigações específicas da experimentação em animais não humanos. Sugere-se que as liçóes aprendidas nas discussóes humanas possam ser transpostas para o animal, o que pode contribuir para uma abordagem mais responsável e sensível(14).

\section{Argumentos a favor e contra o uso de animais}

A ciência biomédica está repleta de métodos que começaram a ser testados em animais. Pode-se dizer que o uso de animais na ciência e no meio acadêmico se divide em três áreas: ensino, pesquisa, e teste de produtos. Dentre essas práticas, está a vivisseção, comum em faculdades biomédicas. $\mathrm{Na}$ psicologia, os animais sáo usados para determinar reaçóes à privação maternal e indução de estresse. Novas drogas também são testadas em animais, assim como diversos procedimentos cirúrgicos e experimentais. Já nas indústrias de cosméticos (produtos de higiene e limpeza) os mesmos são usados para avaliar os graus de toxicidade de novos produtos, além de toxicidade alcoólica, de tabaco e até mesmo de armas químicas(15).

Alguns autores afirmam que a experimentação animal é ilegal, imoral e ineficaz, e sugerem técnicas alternativas que incluem, entre outros, os testes in vitro (realizados em tecidos e células), a utilização de vegetais, os estudos clínicos e não invasivos em humanos voluntários, os estudos epidemiológicos, as técnicas físico-químicas (como a tomografia) e os estudos em cadáveres. Além disso, apoia-se o uso da tecnologia para criar simulaçóes computacionais, softwares educacionais, filmes, modelos matemáticos, nanotecnologia e manequins $(16,17)$. Outros cientistas afirmam que o uso de animais para testar novas drogas e produtos é imprescindível para o avanço da ciência. Entendem que há práticas de experimentação animal necessárias, cujo estudo não existe sem as mesmas, pois não há tecnologia suficiente para substituí-las (16-20).

Graças à legislação, o desenvolvimento de alternativas ligadas ao bem-estar animal, tanto no ensino como na experimentação, já faz parte da realidade brasileira. Estudos nacionais demonstram possibilidades para a substituição do uso de cobaias por métodos alternativos. Uma grande vitória alcançada diz respeito à redução do número de animais utilizados em experimentos científicos.

Mas a polêmica do uso de animais vai além da experimentação. Outras aplicaçóes de animais em função do bem estar humano incluem por exemplo terapia ou atividades assistidas por animais e o uso de animais para propósitos educativos e sociais. Refletindo nesses casos, a recomendação geral é de que as pesquisas garantam os benefícios dessa interaçáo e que sejam seguidas estritamente condiçóes que assegurem o direito ao bem-estar $\operatorname{animal}(21)$.

\section{Por que testar animais para tratar humanos?}

O uso frequente dos modelos animais em pesquisas biomédicas reflete sua validade prática, isto é, sua capacidade de sugerir conclusôes válidas com 
base nas informaçóes deles derivadas. Entretanto, conforme dito anteriormente, alguns argumentos consideram esta prática cientificamente pouco informativa e, de certa forma, imoral. Alguns argumentos justificam essa ideia. Por exemplo, certos autores consideram os modelos animais como pseudociência e, portanto, seus resultados seriam pouco válidos. Entretanto, um modelo animal não é considerado uma teoria, mas um conjunto de hipóteses auxiliares para serem agregadas à ideia em questáo. Outro argumento gira em torno da analogia, entendendo que se deve considerar o poder preditivo do achado em questáo. Se o modelo animal não se conectar apropriadamente a hipóteses e consequências humanas, então ele não será válido. Sendo assim, a validade da modelagem animal se torna uma questáo importante no contexto amplo e controverso da ética sobre experimentação animal(22).

\section{Como os dilemas éticos podem contribuir para a pesquisa em animais?}

Acredita-se que a crescente legislação no Reino Unido tem melhorado a qualidade dos projetos de pesquisa, e isso se deve principalmente à melhora da abordagem ética que a melhoras na metodologia científica em si(23). Quando os cientistas são obrigados a refletir sobre as práticas existentes e enfrentar implicaçôes éticas de seu trabalho, ao mesmo tempo são forçados a confrontar suposições com a necessidade de se buscar soluçóes reais em um mundo de interesses conflitantes(7).

A avaliação ética permite aos cientistas identificarem situaçóes em que as questóes éticas estão embutidas e que, de outra forma, não seriam consideradas. Além disso, o processo ajuda a garantir a imparcialidade das decisões e a obtenção de uma opção benéfica do ponto de vista do bem-estar animal, humano e ambiental. Por último, o processo oferece a oportunidade de ser transparente sobre as fontes potenciais de vieses, considerando se os valores e interesses refletem do conjunto da sociedade ou apenas do(s) tomador(es) de decisão. Esse nível de consideração fornece maior segurança não apenas por ser imparcial, mas porque uma consideração democrática será dada por todos os intervenientes(7).
As publicações científicas são tradicionalmente os meios mais comuns de comunicar resultados, e constituem uma importante fonte de conhecimento. Assim, os trabalhos científicos devem conter informaçóes relevantes sobre os objetivos experimentais, as características dos animais, os métodos usados e os resultados obtidos, a fim de permitir avaliação crítica de seus achados, assim como sua reprodutibilidade. Pesquisas bem planejadas, em conjunto com uma análise estatística adequada, permitem aos investigadores aumentar a robustez e a validade de seus resultados experimentais, pois maximizam o conhecimento adquirido enquanto que minimizam o número de animais utilizados(24).

Apesar disso, por não serem veterinários, a maioria dos editores e revisores de jornais biomédicos não tem ideia do que constitui padróes apropriados de tratamento animal em pesquisa. Além disso, a variedade de culturas e legislações permite uma perspectiva diferente do bem-estar animal entre países. No esforço de melhorar a abordagem, tem sido estudada a inclusão alguns requerimentos sobre os direitos do bem estar animal nas instruçóes aos autores em revistas internacionais, para que sejam cumpridas normas éticas onde quer que o estudo tenha sido conduzido(25).

\section{Abusos Bioéticos: agressão a pesquisadores}

A Bioética corresponde simplesmente à aplicação de noçôes filosóficas aos problemas científicos ou a uma reformulação da deontologia. É uma forma de deliberação que considera normas sociais, culturais e religiosas acerca daquilo que é entendido como eticamente propício, bom e justo(1). Apesar da maioria das pessoas concordar que o uso de animais nas pesquisas é essencial, nos últimos cinco anos, ativistas do direito animal perpetraram uma série de ataques violentos contra pesquisadores. Ameaças anônimas, protesto, vandalismo, libertação de animais, agressóes físicas e explosôes, são exemplos de algumas manifestaçóes(26).

Apesar disso, apenas uma pequena parcela dos pesquisadores que foram atingidos negativamente por tais protestos mudou sua direção. Pesquisas têm mostrado que a reflexão pessoal sobre questóes éticas tende a ser mais eficaz que o ativismo em si na mudança de comportamento dos pesqui- 
sadores. Dentre outras atitudes, a comunicação com o público deveria ser aprimorada através de programas de extensão que envolvam a população e expliquem a importância do desenvolvimento das pesquisas (26). Além da conduta humana preconizada pelos três " $\mathrm{R}$ " e o adequado tratamento dos animais, deve-se seguir, sem fanatismo, o que é direito dos animais como seres vivos. Isso é o que deveríamos esperar das leis de regulamentação da pesquisa animal, assim como da formação dos pesquisadores (1).

\section{Conclusóes}

De acordo com a literatura apresentada, fica claro que todo cientista deveria saber reconhecer incompatibilidades entre a ética e a biologia das questóes de pesquisa. Em alguns casos, poderia se colocar forte peso sobre a ética em relação à proposta científica(27). No entanto, isso não significa que a ciência deve ser totalmente abandonada em função das preocupaçóes éticas. A ética deve se somar aos domínios científicos, aprimorando a tomada de decisão. Por fim, preconiza-se na verdade, um equilíbrio entre as reflexóes éticas e as soluçóes reais(7).

De maneira geral, é evidente a contribuição dos animais para o Homem. Apesar de serem organismos diferentes, concorda-se que muitas descobertas importantes para a humanidade foram desenvolvidas primeiramente em animais e transportadas com maior segurança ao humano. Nesses termos, cabe moralmente ao Homem, como ser racional, garantir um tratamento digno aos animais que contribuem para os avanços da pesquisa. A forma mais segura de seguir este caminho é estabelecendo leis claras e pesquisas bem delineadas, envolvendo a sociedade para designar as normas éticas. Atualmente, é na busca desses ideais que toda e qualquer atividade de pesquisa em animal deveria estar concentrada. 


\section{Referências}

1. Lolas F. Bioethics and animal research. A personal perspective and a note on the contribution of Fritz Jahr. Biol Res 2008; 41(1): 119-123.

2. Hagen K, Van den Bos R, de Cock Buning T. Editorial: Concepts of Animal Welfare. Acta Biotheor 2011; 59(2): 93103.0

3. Jahr F. Bio-Ethik: Eine Umschau über die ethischen Beziehungen des Menschen zu Tier und Pflanze. Kosmos 1927; 24(1): 2-4.

4. Russell WMS, Burch RL. The Principles of Humane Experimental Technique. London: Methuen; 1959.

5. Mellor DJ. Animal emotions, behavior and the promotion of positive welfare states. NZ Vet J 2012; 60(1): 1-8.

6. Petroianu A. Aspectos éticos na pesquisa em animais. Acta Cir Bras 1996; 11: 157-164.

7. Croney CC, Anthony R. Engaging science in a climate of values: tools for animal scientists tasked with addressing ethical problems. J Anim Sci 2010; 88(13 Suppl): E75-E81.

8. Nyika A. Animal research ethics in Africa: An overview. Acta Trop 2009; 112(Suppl 1): S48-S52.

9. Hartung T. Comparative analysis of the revised directive 2010/63/EU for the protection of laboratory animals with its predecessor 86/609/EEC - a t4 report. Altex 2010, 27(4): 285-303.

10. Brasil (2008). Lei $n^{\circ} 11.794$. Regulamenta o inciso VII do $₫ 1$ o do art. 225 da Constituiçáo Federal, estabelecendo procedimentos para o uso científico de animais; revoga a Lei n 6.638, de 8 de maio de 1979; e dá outras providências. Publicada no Diário Oficial da União de 08.10.2008. Disponível em: http://www.planalto.gov.br/ccivil_03/_ato20072010/2008/lei/l11794.htm Acesso em: 6 jul. 2014.

11. Brasil (2009). Decreto no 6.899. Dispóe sobre a composição do Conselho Nacional de Controle de Experimentação Animal - CONCEA, estabelece as normas para o seu funcionamento e de sua Secretaria-Executiva, cria o Cadastro das Instituiçóes de Uso Científico de Animais - CIUCA, mediante a regulamentação da Lei no 11.794, de 8 de outubro de 2008, que dispóe sobre procedimentos para o uso científico de animais, e dá outras providências. Publicada no Diário Oficial da União de 15.07.2009. Disponível em: http://www.planalto.gov.br/ccivil_03/_Ato2007-2010/2009/Decreto/ D6899.htm Acesso em: 6 jul. 2011.

12. Mepham B. A framework for the ethical analysis of novel foods: The ethical matrix. J Agric Environ Ethics 2000; 12 : $165-176$

13. Campbell C, Hare J. Ethical literacy in gerontology programs. Gerontol Geriatr Educ 1997; 17: 3-16.

14. Johnson J. Vulnerable subjects? The case of nonhuman animals in experimentation. J Bioeth Inq 2013; 10(4): $497-504$.

15. Bottini AA, Hartung T. Food for Thought on the Economics of Animal Testing. ALTEX 2009; 26(1): 3-16.

16. Greif S. Alternativas ao Uso de Animais Vivos na Educação - pela ciência responsável. São Paulo: Instituto Nina Rosa; 2003.

17. Greif S, Tréz T. A Verdadeira Face da Experimentaçáo Animal - a sua saúde em perigo. Rio de Janeiro: Editora Falabicho; 2000.

18. Schramm FR. 2002. Bioética para quê? Revista Camiliana da Saúde 2002; 1: 14-21.

19. Goldim JR, Raymundo MM. Pesquisa em Saúde e os Direitos dos Animais. 2a ed. Porto Alegre: HCPA; 1997.

20. Tréz T, Greif S. A Verdadeira Face da Experimentação Animal. 2a edição, Rio de Janeiro: Editora; 2000.

21. Santori P. Problems related to the use of animals for therapeutic and care purposes. The documento of the National Committee for Bioethics. 2011. Ann Ist Super Sanita 2011; 47(4): 349-352.

22. Shelley C. Why test animals to treat humans? On the validity of animal models. Stud Hist Philos Biol Biomed Sci 2010; 41(3): 292-299.

23. Purchase IFH, Nedeva M. The impact of the introduction of the ethical review process for research using animals in the UK: implementation of policy. Lab Anim 2002; 36(1): 68-85.

24. Kilkenny C, Parsons N, Kadyszewski E, Festing MFW, Cuthill IC, et al. Survey of the Quality of Experimental Design, Statistical Analysis and Reporting of Research Using Animals. PLoS One 2009; 4(11): e7824.

25. Clutton RE, Clarke KW, Pascoe PJ. Animal welfare in biomedical publishing. Vet Anaesth Analg 2011; 38(1): 1-2.

26. Cressey D. Animal Research: Battle scars. Nature 2011; 470(7335): 452-453.

27. Siegford JM. Bioethics Symposium: A scientist's guide to approaching bioethics. J Anim Sci. 2010; 88(13 Suppl): E73-E74.

Recebido: 26 de junho de 2012

Aceito: 20 de dezembro de 2012 